\title{
Update from RCP Quality Improvement: supporting and learning with the next generation of 'improvers'
}

This part of the Future Healthcare Journal is where you will find regular updates on the work of the RCP Quality Improvement Programme.

We very much welcome your feedback. If you have any comments, or would like to be involved in the work of the Programme, please contact RCPQI@rcplondon.ac.uk.

Times are changing. There was a time when service development or changes in the processes of care were the remit of the clinical director, lead consultant or senior nurse. Then came the recognition that certain approaches to delivering change may lead to more successful implementation in healthcare as well as in other 'industries'. This is what became known as quality improvement or QI. Initially there were a growing band of enthusiasts for QI in many developed countries, and gradually more healthcare professionals and managers have recognised the benefit of taking these approaches. Around 10 years ago the concept that early career healthcare professionals could be the agents for significant change and improvement was developing, and the Institute for Healthcare Improvement developed IHI Open School, an online community of healthcare professionals in training, who wanted to be involved in QI. To date around 600,000 students have completed courses in the Open School. ${ }^{2}$ In the NHS at around the same time early career doctors began to be involved in QI projects through local opportunities and the Royal College of Physicians's Learning to make a difference programme. Now, learning the practice of QI is a curriculum requirement for foundation doctors, core medical trainees (CMTs), and specialist trainees in some specialties, including the new internal medicine curriculum. Some undergraduate medical courses also include special studies modules in QI.

Doctors and other healthcare professionals in training recognise opportunities to improve care on a daily basis and are generally enthusiastic to make this happen. Now that taking part in and learning through QI projects is a requirement for them, there is a massive potential to benefit patients through this enthusiasm and opportunity. As with all elements of professional practice, enthusiasm, opportunity and curriculum requirements are not enough to ensure practice develops in the best way. There needs to be structured support teaching evidence-based approaches, and enabling learning through practice.

For many established doctors their first exposure to QI may have been through trainees they are working with or supervising. The most common reasons trainees tell us that they don't realise the benefits of learning through QI projects are lack of time and the fact that their supervisors don't understand what they need to do, and what they need to learn in QI.

RCPQI has worked with colleagues in RCP education to produce an e-learning short programme Supervising Quality improvement
Projects - A guide for supervisors. This is now available at www. rcplondon.ac.uk/education-practice/courses/e-learning-rcp. It aims to help supervisors of doctors in training to understand how they can support their trainees to learn through being part of a QI project. It also has links for supervisors or trainees to additional opportunities to learn more about QI. IHI Open School modules are also free to all doctors in training and can be accessed at www. ihi.org/education/ihiopenschool/overview. There has been variable understanding of what trainees need to do in QI projects. This is also clarified in the guide for supervisors and for CMTs. ${ }^{3}$

The RCP's chief registrar scheme gives around 50 senior trainees in medical and other specialties the opportunity to learn leadership in practice, and QI is an important component of this. They spend $40 \%$ of their time in the year within their organisation on leadership, management, education and QI. The work done by the $2017 / 18$ cohort can be seen in their yearbook. ${ }^{4}$ Expressions of interest for 2019/20 are now open too. ${ }^{5}$ Their knowledge and skills will be so important to future service improvement.

RCPQI also see the sharing of trainees' QI projects as an important part of the RCP's role. There will be opportunities at regional RCP 'Updates', RCP 'Trainees conference', and 'Innovation in Medicine 2019'. We are also working with Future Healthcare Journal to ensure a route to publishing both short summaries and peer-reviewed papers from projects.

Many organisations and individuals have a role in supporting the next generation of 'improvers'. A core curriculum for quality improvement and patient safety is being developed through the Academy of Medical Royal Colleges, foundation schools and schools of medicine will ensure that there are opportunities for supported learning and high-quality assessment. NHS trusts and boards should have a QI infrastructure and expertise to support all staff, and this includes doctors in training. Ensuring that projects are team based, linked to organisational priorities, and that they continue when the trainee moves on is important. As with other components of professional development, local champions and role models often have the biggest impact on trainees. Rebecca Inglis, a senior trainee in critical care, summarised trainees' experience of what helps successful projects and learning during a presentation at 'The International Forum for Quality and Safety in Healthcare' in 2017. This is shown in Fig 1. RCPQI is developing resources, opportunities and advice. Doctors in training might be seen as the next generation of 'improvers', but the reality is they are the current generation of improvers, and many of us are learning with them, from their passion for excellent care, enthusiasm to deliver successful change, and increasingly their skills in doing this, which may be more developed than in many of their senior colleagues.

John Dean

Clinical director for quality improvement and patient safety, Royal College of Physicians 


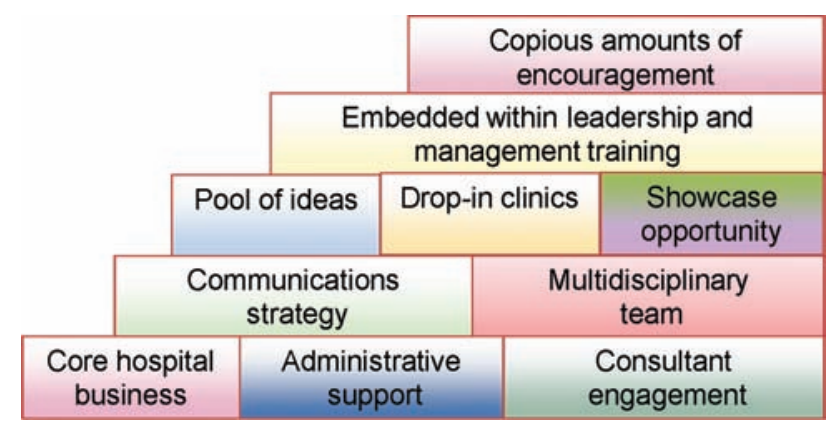

Fig 1. Factors to support doctors in training in quality improvement projects.

\section{References}

1 The Health Foundation. Quality improvement made simple, 2013. www.health.org.uk/publication/quality-improvement-made-simple [Accessed 31 August 2018].

2 Institute for Healthcare Improvement. IHIOpen School. www.ihi.org/ education/ihiopenschool/overview/ [Accessed 31 August 2018].

3 Royal College of Physicians. Guidance on engaging core medical trainees in quality improvement. www.rcplondon.ac.uk/projects/outputs/guidanceengaging-core-medical-trainees-quality-improvement [Accessed 31 August 2018].

4 Royal College of Physicians. RCP chief registrar alumni. www. rcplondon.ac.uk/projects/outputs/rcp-chief-registrar-alumni [Accessed 31 August 2018].

5 Royal College of Physicians. Chief registrar: 2019-20 recruitment guidance. www.rcplondon.ac.uk/projects/outputs/chief-registrar2019-20-recruitment-guidance [Accessed 31 August 2018]. 